\title{
Correction to: Neonatal Diabetes Mellitus: Novel Mutations
}

\author{
Sapna Nayak ${ }^{1}$ - Aditya Narayan Sarangi ${ }^{2}$ - Saroj Kumar Sahoo ${ }^{1}$ - Pragya Mangla ${ }^{1}$ - Manoranjan Tripathy ${ }^{1}$. \\ Sudha Rao ${ }^{3}$. Suchit Gupta ${ }^{1}$ - Vimal Kumar Paliwal ${ }^{4}$. Siddhnath Sudhanshu ${ }^{1} \cdot$ Chaitra Ravi $^{1} \cdot$ Kriti Joshi $^{1}$. \\ Vijayalakshmi Bhatia ${ }^{1} \cdot$ Eesh Bhatia ${ }^{1}$
}

Published online: 29 April 2021

(C) Dr. K C Chaudhuri Foundation 2021

\section{Correction to: The Indian Journal of Pediatrics https://doi.org/10.1007/s12098-020-03567-7}

1. In Table 1: The nucleotide change in patient 2 of table 1 should have been c.402delC in place of c.399delC, as mentioned in the paper.

2. In Table 2: Under the column "mutations identified" in EIF2AK3 (row 3), the codon number requires correction as p.Cys $769^{*}$ in place of p.Cys $768^{*}$.

The discrepancy arose during reannotation using reference sequence NM_004836.7; the reference sequence AF110146.1 had been used by the reporting laboratory.

The original article has been corrected.

Publisher's Note Springer Nature remains neutral with regard to jurisdictional claims in published maps and institutional affiliations.

The online version of the original article can be found at https://doi.org/ $10.1007 /$ s12098-020-03567-7

Vijayalakshmi Bhatia

bhatiaviji@gmail.com

1 Department of Endocrinology, Sanjay Gandhi Postgraduate Institute of Medical Sciences, Lucknow, Uttar Pradesh 226014, India

2 Biomedical Informatics Center, Sanjay Gandhi Postgraduate Institute of Medical Sciences, Lucknow, Uttar Pradesh, India

3 Department of Pediatrics, B. J. Wadia Hospital for Children, Mumbai, Maharashtra, India

4 Department of Neurology, Sanjay Gandhi Postgraduate Institute of Medical Sciences, Lucknow, Uttar Pradesh, India 